\title{
Climate Change: essential knowledge for developing holistic solutions to our climate crisis
}

\section{Mark Maslin}

Department of Geography, University College London, Pearson Building, Gower Street, London, WC1E 6BT

\begin{abstract}
Understanding anthropogenic climate change is essential for anyone working in the life sciences. Firstly because climate change has already started to impact the Earth biosphere and human health and these changes need to be documented and acknowledged. Secondly many of the solutions to climate change, both mitigation and adaptation, will be through the life sciences, everything from massive reforestation and sustainable agriculture to preventing the spread of disease and protecting individual human health. Anthropogenic climate change is, therefore, one of the defining challenges of the $21^{\text {st }}$ century, along with poverty alleviation, environmental degradation and global security. Climate change is no longer just a scientific concern, but encompasses economics, sociology, geopolitics, national and local politics, law, and health to name a few. Hence to understand climate change fully then not only does one have to review the science but also the politics and geopolitics, which have created the issue and can provide the solutions. Climate change ultimately makes us examine the whole basis of modern society and ultimately asks questions about humanity's relationship with the rest of the planet.
\end{abstract}

\section{Introduction}

The impacts of human actions on our home planet are now so large that many scientists are declaring a new phase of Earth's history. The old forces of nature that transformed Earth many millions of years ago, including meteorites and mega-volcanoes are joined by another: us. We have entered a new human-dominated epoch of geological time called the Anthropocene (Lewis and Maslin, 2015; Waters et al., 2016).

The scale of human impacts on Earth's workings is immense. Globally, human activities move more soil, rock and sediment each year than is transported by all other natural processes combined. We have cut down nearly 3 trillion trees, about half of those on the 
planet (Crowther et al. 2015). Factories and farming remove as much nitrogen from the atmosphere as all Earth's natural processes. These changes rival those in Earth's geological history (Lewis and Maslin, 2018).

Humanity has also made enough concrete to cover the entire surface of the Earth in a layer two millimetres thick. Enough plastic has been manufactured to Clingfilm it as well. We produce 4.8 billion tonnes of our top five crops, plus 4.8 billion head of livestock, annually. There are 1.2 billion motor vehicles, 2 billion personal computers, and more mobile phones than the 7.5 billion people on Earth. If you weighed all the land mammals on Earth, $30 \%$ of that weight is us humans, $67 \%$ would be the farm animals that feed us, and just $3 \%$ are mammals living in the wild. A sixth mass extinction in Earth's history looms.

Adding to the human impact on the planet is climate change. The Fifth Assessment Reports (AR5) of the Intergovernmental Panel on Climate Change (IPCC) published in 2013 and 2014 state that the evidence for climate change is unequivocal (IPCC, 2013; 2014a and b).-There is now evidence for a $1^{\circ} \mathrm{C}$ rise in global temperatures and over a $20 \mathrm{~cm}$ rise in sea level in the last 100 years. Depending on how much we control future greenhouse gas (GHG) emissions the global mean surface temperature could rise between $2.8^{\circ} \mathrm{C}$ and $5.4^{\circ} \mathrm{C}$ by the end of the 21st century. In addition global sea level could rise by between $52 \mathrm{~cm}$ and $98 \mathrm{~cm}$ and there will be significant changes in weather patterns with more extreme climate events (IPCC, 2014a). At the UNFCCC COP21 meeting in Paris at the end of 2015 an agreement was reached to avoid the worst effects of climate change by keep global temperature rise below $2^{\circ} \mathrm{C}$ and if possible limit global warming to $1.5^{\circ} \mathrm{C}$. To achieve a $2^{\circ} \mathrm{C}$ target climate models indicate that global carbon emissions must peak by 2020, reach zero between 2060 and 2080 and then become negative through to 2100 . To achieve a $1.5^{\circ} \mathrm{C}$ target then we must do the same but global carbon emissions need to be zero by 2050 at the latest (IPCC, 2018). Hence climate change challenges the fundamental way we generate energy, grow food and consume natural resources. But we must find solutions to climate change, which do not increase our already huge impact on the Earth and also deal with issues of global inequality and security. We require win-win solutions by taking a holistic approach to the challenges of the $21^{\text {st }}$ century. This inevitably leads to conclusion that major changes are required this century to the way we organize society. 


\section{The Role of Greenhouse Gases}

The temperature of the Earth is determined by the balance between energy from Sun and its loss back into space. About one-third of the solar energy is reflected straight back into space (Figure 1). The remaining energy is absorbed by both the land and ocean. This warms them and they then radiate this acquired warmth as long-wave infrared or 'heat' radiation. Atmospheric gases such as water vapour, carbon dioxide, methane, and nitrous oxide are known as greenhouse gases as they can absorb some of this long-wave radiation, thus warming the atmosphere. This effect has been measured in the atmosphere and can be reproduced time and time again in the laboratory. We need this greenhouse effect because without it, the Earth would be at least $35^{\circ} \mathrm{C}$ colder, making the Earth's average surface temperature $-20^{\circ} \mathrm{C}$ (IPCC, 2013). While many of these gases occur naturally in the atmosphere, humans are responsible for increasing their concentration through burning fossil fuels, deforestation and other land use changes. For example records of air bubbles in ancient ice show us that carbon dioxide and other greenhouse gases are now at their highest concentrations for more than 800,000 years (IPCC, 2013).

\section{Causes of Anthropogenic Climate Change}

There is clear evidence that levels of atmospheric carbon dioxide have been rising ever since the beginning of the industrial revolution (IPCC 2013). The first measurements of $\mathrm{CO}_{2}$ concentrations in the atmosphere started in 1958 at an altitude of about 4,000 metres, on the summit of Mauna Loa mountain in Hawaii. The measurements were made here to be remote from local sources of pollution. The record clearly shows that atmospheric concentrations of $\mathrm{CO}_{2}$ have increased every single year since 1958. The mean concentration of approximately 316 parts per million by volume (ppmv) in 1958 has risen to over 410 ppmv now (see Figure 2). The annual variations in the Mauna Loa observatory are mostly due to $\mathrm{CO}_{2}$ uptake by growing plants. The uptake is highest in the Northern Hemisphere springtime; hence every spring there is a drop in atmospheric carbon dioxide, which unfortunately does nothing to the overall trend towards ever-higher values.

The United Nations Framework Convention on Climate Change (UNFCCC) was created to monitor and develop an international agreement on reducing global greenhouse gas emissions (Maslin, 2014). Four-fifths of global carbon dioxide emissions come from 
burning of fossil fuels for energy production, industrial processes, and transport (IPCC, 2014b). North America, Europe, and Asia emit over 90\% of the global industrially produced carbon dioxide (IPCC, 2014b). One-fifth of global carbon dioxide emissions are as a result of land-use changes. These emissions come primarily from the cutting down of forests for the purposes of agriculture, urbanization, and roads. South America, Asia, and Africa are responsible for over $90 \%$ of present-day land-use change emissions (IPCC, 2014b).

The developed countries have historically emitted most of the greenhouse gases. They have been emitting since the start of the industrial revolution in the latter half of the 18th century. Though this historic carbon burden is important, between 2015 and 2044 the world could emit another trillion tonnes of carbon dioxide into the atmosphere (Allen et al., 2009). This is the same amount that was put in between 1750 and 2017. This is partly because rapidly developing countries such as China, India, South Africa, and Brazil are increasing their emissions of greenhouse gases, since economic development is closely associated with energy production. For example, in 2007 China become the biggest emitter of carbon dioxide in the world, overtaking the USA (IPCC, 2014b). However, when considered per capita, the USA emissions are four times higher than those of China (Figureres et al., 2018). Half trillion tonnes of carbon has been put into the atmosphere since the industrial revolution represents only half our total emission. It seems that $~ 50 \%$ of our emission have been absorbed by the Earth with $25 \%$ going into the oceans and $~ 25 \%$ going into the land biosphere (Figure 3). However scientists are concerned as this removal of our pollution is unlikely to continue fully in the future. This is because as global temperatures rise the oceans will warm and will be able to hold less carbon dioxide. As we continue to deforest and convert land for farming and urbanisation there will be less vegetation to absorb carbon dioxide again reducing the uptake of our carbon pollution.

\section{Evidence for Climate Change}

Understanding future climate change is about understanding how science works and the principle of the 'weight of evidence'. Science moves forward by using detailed observation and experimentation to constantly test ideas and theories. Over the last 30 years the theory of climate change must have been one of the most comprehensively tested ideas in science. The IPCC (2013) presents six main lines of evidence for climate change. 
1. We have tracked the unprecedented recent increase in the amount of atmospheric carbon dioxide and other greenhouse gases since the beginning of the industrial revolution (see Figure 2).

2. We know from laboratory and atmospheric measurements that such greenhouse gases do indeed absorb heat when they are present in the atmosphere. The positive and negative effects on the radiative balance of the Earth have been calculated from 1750 (IPCC, 2013), which are consistent with observed temperature rises.

3. We have tracked significant increase in global temperatures of at least $0.85^{\circ} \mathrm{C}$ (Figure 4) and a sea level rise of $20 \mathrm{~cm}$ over the past century.

4. We have analysed the effects of natural events such as sunspots and volcanic eruptions on the climate, and though these are essential to understand the pattern of temperature changes over the past 150 years, they cannot explain the overall warming trend.

5. We have observed significant changes in the Earth's climate system including reduced snowfall in the Northern Hemisphere, retreat of sea ice in the Arctic, retreating glaciers on all continents, and shrinking of the area covered by permafrost and the increasing depth of its active layer. All of which are consistent with a warming global climate.

6. We continually track global weather and have seen significant shifts in weather patterns and an increase in extreme events all around the world. Patterns of precipitation (rainfall and snowfall) have changed, with parts of North and South America, Europe and northern and central Asia becoming wetter, while the Sahel region of central Africa, southern Africa, the Mediterranean and southern Asia have become drier. Intense rainfall has become more frequent, along with major flooding. We're also seeing more heat waves. According to the US National Oceanic and Atmospheric Administration (NOAA) between 1880 and 2018, the 19 warmest years on record have all occurred within the past 20 years; and 2016 was the warmest year ever recorded.

\section{Future changes in climate}

Continued burning of fossil fuels will inevitably lead to a further warming of our climate. The complexity of the climate system is such that the extent of such warming is difficult to predict, particularly as the largest unknown is how much greenhouse gas we as a global society will emit over the next eighty-five years (Maslin, 2013). The IPCC developed a range 
of emissions scenarios or Representative Concentration Pathways (RCPs) to examine the possible range of future climate change. These include key assumptions about the increase in the amount and type of world trade and the growth of the World's population (van Vuuren et al., 2011). Three RCPs are realistic scenarios including a 'business as usual' one (RCP 8.5) and one that examines what needs to be done in terms of greenhouse gas emissions to keep climate change beneath $2^{\circ} \mathrm{C}$ (RCP 2.6). Using the three main realistic RCPs over the next eighty-five years, the climate model projections suggest the global mean surface temperature could rise by between $2.8^{\circ} \mathrm{C}$ and $5.4^{\circ} \mathrm{C}$ by the end of the $21^{\text {st }}$ century (Figure 5a). Sea level is projected to rise by between $52 \mathrm{~cm}$ and $98 \mathrm{~cm}$ by 2100, threatening coastal cities, low-lying deltas and small islands (Figure 5b). Extents of snow cover and sea ice are projected to continue to reduce, and some models suggest that the Arctic could be ice-free in late summer by the latter part of the $21^{\text {st }}$ century. Heat waves, extreme rainfall events and flash flood risks are projected to increase, posing potential threats to health, ecosystems, and human settlements and security (Costello et al., 2009; Watts et al., 2015). Even if global greenhouse gas emissions were to be cut immediately, there would still be some level of ongoing warming for decades and some sea level rise continuing for centuries, because the climate system is slow to respond fully to imposed changes (IPCC, 2018).

These changes will not be spread uniformly around the world (IPCC, 2014a). Some regions will warm faster than the global average, while others will warm more slowly. Faster warming is expected near the poles, as the melting snow and sea ice exposes the darker underlying land and ocean surfaces which then absorb more of the sun's radiation instead of reflecting it back to space in the way that brighter ice and snow do. Indeed, such 'polar amplification' of global warming is already being seen. The expansion of tree and shrub cover already being observed in some tundra regions is expected to continue as the climate warms further, and permafrost is projected to continue to thaw. Changes in precipitation are also expected to vary from place to place. In the high-latitude regions (central and northern regions of Europe, Asia and North America) the year-round average precipitation is projected to increase, while in most sub-tropical land regions it is projected to decrease by as much as $20 \%$. This would increase the risk of drought and, in combination with higher temperatures, threaten agricultural productivity. However, this may be offset to some extent by the effects of rising carbon dioxide on plants, which can enhance growth and also reduce their water requirements. In many other regions of the world, species and 
ecosystems may experience climatic conditions at the limits of their optimal or tolerable ranges or beyond. They may also be subject to competition from invasive species becoming established in newly-favourable climates. Human land use conversion for food, fuel, fibre and fodder, combined with targeted hunting and harvesting, has resulted in species extinctions some 100 to 1000 times higher than background rates (reference). Climate change will exacerbate this changing ecosystem composition and the accelerating extinction rates (Garcia et al., 2014). As well as impacting on biodiversity, such ecological changes may feed back into the processes of climate change by reducing the strength of the natural carbon sink, which is currently offsetting some of the human emissions of carbon dioxide (IPCC, 2014a).

\section{Ocean Acidification}

Sea level rise is usually considered the main effect on the marine system due to climate change but direct measurements of the ocean's chemistry have shown that it is also causing ocean acidification (Barker and Ridgwell, 2012; Birchenough et al., 2017). This is because carbon dioxide in the atmosphere dissolves in the water of the surface ocean (IPCC, 2013). This is controlled by two main factors, the amount of carbon dioxide in the atmosphere and the temperature of the ocean (Birchenough et al., 2017). The oceans have already absorbed about a third of the carbon dioxide resulting from human activities, which has lead to a steady decrease in ocean $\mathrm{pH}$ levels. With increasing atmospheric carbon dioxide in the future the amount of dissolved carbon dioxide in the ocean will continue to increase (Figure 6). Some marine organisms, such as corals, foraminifera, coccoliths and shellfish, have shells composed of calcium carbonate, which dissolves more readily in acid. Laboratory and field experiments show that under high carbon dioxide the more acidic waters cause some marine species to have misshapen shells and lower growth rates, although the effect varies among species. Acidification also alters the cycling of nutrients and many other elements and compounds in the ocean, and it is likely to shift the competitive advantage among species, and have impacts on marine ecosystems and the food web (Barker and Ridgwell, 2012; IPCC, 2014b; Birchenough et al., 2017). This is a major worry as fishing is still a major source food, with about 95 million tonnes caught by commercial fishing and another 50 million tonnes produced by fish farms per year. 


\section{Potential health impacts of climate change}

The potential health impacts of climate change are immense and managing those impacts will be an enormous challenge (Watts et al., 2015; 2018). Climate change will increase deaths from heat waves, droughts, storms and floods. However higher global temperatures will also be a challenge for many societies, particularly those that rely heavily on subsistence agriculture. As higher air temperatures and humidity will make working outside more difficult and increasing the likelihood of hyperthermia; already it is estimated that 3.4 billion weeks of outside labour were lost in 2017 (Watts et al., 2018). This will also impact the health of anyone who has to work outside regularly including construction workers and farm workers (Watts et al., 2015; 2018).

The major effect of climate change in terms of global health is the potential increase in water and food insecurity that could impact billions of people (Costello et al., 2009; Watts et al., 2015). The most important threat to human health is access to fresh drinking water. At present there are still 1 billion people that do not have regular access to clean safe drinking water (Papworth et al., 2014). Not only does the lack of water cause major health problems from dehydration but a large number of diseases and parasites are present in dirty water. Rising human populations, particularly growing concentrations in urban areas, are putting great stress on water resources. The impacts of climate change - including changes in temperature, precipitation, and sea levels - are expected to have varying consequences for the availability of fresh water around the world. For example, changes in river run-off will affect the yields of rivers and reservoirs and thus the recharging of groundwater supplies (Taylor et al., 2013; Taylor, 2014). An increase in the rate of evaporation will also affect water supplies and contribute to the salinization of irrigated agricultural lands. Rising sea levels may result in saline intrusion in coastal aquifers. Currently, approximately 1.7 billion people, one-quarter of the world's population, live in countries that are water-stressed (Watts, et al., 2017).

Human health is threatened by the lack of access to affordable basic food. Future changes in temperatures, precipitation and length of growing season will all affect the production of food and other agricultural goods. Extreme weather events must also be considered and now the contribution of climate change can be calculated through attribution studies (BAMS, 2017). For example the 2010 Russian heat wave led to serve droughts that reduced grain production so much that Russia banned their export to ensure 
there was enough for their own country (BAMS, 2017). Between 2007 and 2011 drought affected much of Syria resulting in the loss of $75 \%$ of crops and $85 \%$ of livestock (BAMS, 2017). With an increasingly globalised economy very few countries are self-sufficient in basic food and hence food imports are very important. However access to basic food is also about cost and food prices since 2004 have increasing by $80 \%$ due to the price of oil, increased overall demand, biofuel production, and natural disasters (Lagi et al., 2012). The expansion of meat-eating in developing countries such as India and China is an important forcing factor, because beef cattle require $8 \mathrm{~kg}$ of grain or meal for every kilogram of flesh they produce. In 2008-2009 there was a 60\% rise in the price of food and in 2011-12 there was a $40 \%$ jump in price these price spikes have been attributed to food speculation on the global markets (Lagi et al., 2012).

\section{Direct impact of climate change on the UK}

Climate change is making the climate of the UK more seasonal and increasing the variability of our weather (UKCP, 2018). UK winters are becoming warmer and much wetter but with short sharp intense cold periods like the 2018 'Beast from the East'. Future predations are that winters will be more like those of 2000, 2007 and 2013/14 when the UK was hit with devastating floods. UK summers are becoming warmer and drier and future summers will be hot and very dry and more like the droughts and heat-waves of 1976, 2003, 2007 and 2018. The UKCP (2018) also suggests that if greenhouse gas emissions are not reduced then UK summers could be at least $5^{\circ} \mathrm{C}$ hot on average by 2050 . Sea level rise will threaten coastal cities and communities and it will increase the severity of flooding and the impact of storm surges. For details on predicted changes in the USA please refer to the Fourth National Climate Assessment (NCA, 2018).

\section{IPCC $1.5^{\circ} \mathrm{C}$ Global Warming report}

The IPCC (2018) special report on keeping global warming to below $1.5{ }^{\circ} \mathrm{C}$ above preindustrial levels reviews the potential impacts of climate change up to $2^{\circ} \mathrm{C}$ warming and demonstrates there would already be highly significant changes to Arctic regions, coastal areas, agricultural production and human health. The report also provides global greenhouse gas emission pathways that would allow the World to keep warming below $1.5^{\circ} \mathrm{C}$ (Figure 7) while maintaining sustainable development and eradicating poverty. 
Though the major challenge is to reduce emissions from energy generation, land-use changes is an essential element of any global solution. The IPCC (2018) special report directly links the UN Sustainability Goals (Georgeson and Maslin, 2018) and the mitigation and adaption to climate change.

All the model pathways to a future $1.5^{\circ} \mathrm{C}$ World contain significant contributions from agriculture and forestry. These include conversion of up to 8 million $\mathrm{km}^{2}$ of pasture and up to 5 million $\mathrm{km}^{2}$ of non-pasture agricultural land used for food and feed crops into a minimum of 7 million $\mathrm{km}^{2}$ for energy crops. These energy crops will produce solid and liquid fuel that will replace fossil fuels. IPCC (2018) also include aggressive global reforestation targets to take the current 1 million $\mathrm{km}^{2}$ reduction in forest and shift it to a 10 million $\mathrm{km}^{2}$ increase in forests by 2050 . The IPCC (2018) state that such large transitions pose profound challenges for sustainable management of the various demands on land for human settlements, food, livestock feed, fibre, bioenergy, carbon storage, biodiversity and other ecosystem services. Options to reduce carbon emissions from human land-use could include sustainable intensification of land use practices, ecosystem restoration and changes towards less resource-intensive diets. This would mean overcoming significant socioeconomic, institutional, technological, financing and environmental barriers. But considering that humans have cut down over half the trees on Earth, over 3 trillion trees, there is ample opportunity and land on which to reforest (Crowther et al., 2015). Despite the rising population of the Earth, projected to hit 10 billion by 2050 (Stephenson et al., 2013), there is a net migration from the rural areas into urban areas. Hence the World is getting wilder as people are living on more dense population. This provides more areas that can be considered for rewilding.

\section{Perfect Storm}

Climate change is at the centre of what Prof. Sir John Beddington (previous UK Government Chief Scientific Adviser) called the 'perfect storm' (Sample, 2009). By 2030 global food and energy demand will have increased by $50 \%$ and water requirement will have increased by $30 \%$. This is partly due to the rise in global population but is also caused by the rapid development of lower income countries and a huge increase in consumption. According to the UN predictions global population will grow to 10 billion people by 2050 and then it will 
stabilise and may even drop slightly. However that means there will be another 2 billion people on the Planet in the next 35 years (Stephenson et al., 2013).

Given this background the challenge set by politicians at COP21 in Paris is truly daunting. Because to achieve the $1.5^{\circ} \mathrm{C}$ target climate models indicate that global carbon emissions must peak by 2020, reach zero by the latest 2050 and then become negative through to 2100 (IPCC, 2018). This is made harder as there are multiple global challenges in the $21^{\text {st }}$ century that require action including; extreme poverty, environmental degradation, global security as well as climate change. So solutions should always contain an element of win-win. For example supporting a huge increase in renewable energy not only reduces emissions but helps to provide energy security by reducing the reliance on imported oil, coal and gas. It also reduces air pollution and thus enhances human health (Watts et al., 2018). Reduced deforestation and reforestation should not only draw-down additional carbon dioxide from the atmosphere but help to retain biodiversity, stabilize soils and local rainfall and provide livelihoods for local people via carbon credits. Measures that reduce car use will increase walking and cycling, which in turn reduce obesity and heart attacks (Costello, et al., 2009). Ensuring that women are educated to at least secondary school level all around the world, empowers them to take control of their own fertility, which in turns helps stabilise population growth and pressures on development (Stephenson et al., 2013).

\section{Solutions}

Reducing greenhouse gas (GHG) emissions is a major challenge for our global society. This should not be underestimated because despite 30 years of climate change negotiations there has been very little deviation in GHG emissions from the 'business as usual' pathway. The failure of the international climate negotiation, most notably at Copenhagen in 2009, set back meaningful global cuts in GHG emissions by at least a decade; though some of this momentum has been regained at Paris in 2015. There is also a strong economic argument for taking action. It is estimated that tackling climate change now would cost between $2-3 \%$ of World GDP, as opposed to over $20 \%$ if we put off action till the middle of the century (Stern, 2007). Even if the benefits were not so great, the ethical case for paying now to prevent the deaths of tens of millions of people and avoiding a significant increase in human misery must be clear (Watts et al., 2015). 
The fundamental issue at the heart of climate change and humanity's increasing environmental footprint in the planet is consumption. To create a new way of living the core dynamic of ever-greater production and consumption of goods and resources must, therefore, be broken, coupled with a societal focus on repairing the environmental damage of the past. Two increasingly discussed ideas do just this.

Universal Basic Income (UBI) is a policy whereby a financial payment is made to every citizen, unconditionally, without any obligation to work, at a level above their subsistence needs (Painter and Thoung, 2015). Small-scale trials of UBI shows that educational attainment is higher, healthcare costs go down, entrepreneurship levels go up, as does selfreported happiness increases. However, UBI does more than this: it could break the link between work and consumption (Painter and Thoung, 2015).

The requirement for most of us to sell our labour and be ever more productive is compensated for by enabling us to increase our consumption. Given this dynamic, it makes little sense to forgo environmentally damaging behaviour when we know we have to work harder in the future regardless of our choices. Consumption is the pay-back for being evermore productive at work. People often tell themselves that they deserve that lunch of foodstuffs sourced from thousands of miles away, new car, or long-haul holiday. They say: I'm working hard, I've earned it.

By breaking this link between work and consumption UBI can, if carefully managed over time, dramatically lessen environmental impacts (Lewis and Maslin, 2018). People could work less and consume less, and still meet our needs. Fear for the future would recede, meaning we would not have to work ever-harder for fear of having no work in the future. Particularly as automation and intelligent machines will reduce the numbers of jobs available.

As a systemic change UBI eliminates extreme poverty and reduces dependency, giving people the agency to say 'no' to undesirable work, and 'yes' to opportunities that often lie out of reach. Nobody would be under any obligation to do environmentally damaging types of work - those in the fossil fuel industries would have the security of income to retrain. 
Overall, with UBI people would be able to plan for the future and would be able to 'afford the luxury' of taking action now to avoid negative environmental impacts on future generations. With UBI we could all think long-term, well beyond the next payday (Painter and Thoung, 2015). We could care for ourselves, others, and the wider world, as living in a sustainable future demands (Lewis and Maslin, 2019).

Environmental repair could come from the simple but profound idea that we allocate half the Earth's surface primarily for the benefit of other species. Half-Earth is less utopian than it first appears, as we have become an urban species. Mass-scale forest restoration is already underway, with commitments across 43 countries to restore 292 million hectares of degraded land to forest, ten times the area of the UK (Lewis et al., 2019).

And at a deeper level, our views on nature are forged by the society we live in. The idea of pristine nature in separate National Parks emerged in opposition to the pollution of the Industrial Revolution. Acknowledging our immense impacts re-establishes that humans are part of nature, and so rewilding projects, where large areas are managed to allow natural processes to run, are increasingly popular. Slowly, a new nature aesthetic is being born.

But can we really escape booming production and consumption? The fate of species encountering vast new resources is exponential growth and then collapse, epitomised by the rapid expansion and eventual death of bacteria growing in a Petri dish. While rarely recognised, we humans have recently become the exception to this rule: birth rates on all continents are declining or have already stabilised. The global population will not double in size again, and will probably stop growing altogether by mid-century (Stephenson et al., 2013). This is all because of more information, in the form of girl's education - which is a key determinant of family size. Humans are unique in four billion years of life on Earth by being able to stablize our own population. In this case progressive goals and planetary stewardship go hand-in-hand.

Build on this, UBI would give people the right to choose when it comes to fulfilling their own basic needs and rewilding Earth does the same of other species' needs. With carefully designed policies that unleash dynamics that push society towards a new mode of living for 
a new epoch, we can do what is necessary: to reduce human suffering, enable people to flourish and not destroy the life-supporting infrastructure of Earth in the process.

International agreements will also have to acknowledge and deal with the role world trade plays in driving carbon emissions. Climate change policies and laws based around international negotiations must also be implemented at both regional and national level to provide multi-levels of governance to ensure these cuts in emissions really do occur (Maslin and Scott, 2011). Novel ways of redistributing wealth, globally and well as within nationstates, are needed to lift billions of people out of poverty without huge increases in consumption, resource depletion and GHG emissions. Support and money is also need to help developing countries to adapt to the climate changes that will inevitably happen (IPCC 2014a). World trade has been instrumental in the rapid expansion of global wealth but more focus is required on its negative impacts, both in terms of driving carbon emission and exacerbating food, water and resource insecurity.

\section{Conclusions}

The science of climate change is clear and world leaders have now decided to act to avoid the worst effects by keeping global temperature rises to less than $2^{\circ} \mathrm{C}$ and if possible below $1.5^{\circ} \mathrm{C}$. To achieve this aim cheap and clean energy production is required, as all economic development is based on increasing energy usage. Countries need to focus on localised renewable energy production to cut down on both the use and transport of fossil fuels. Fossil fuel subsidies should be made illegal and sanctions applied to countries, which continue to skew the world's energy markets. The International Monetary Fund report estimated direct fossil subsides are $£ 1.3$ trillion per year and if the cost of air pollution and climate change are added this rises to $£ 5.3$ trillion per year which is $\sim 6.5 \%$ of global GDP (Coady et al., 2015). The International Energy Agency estimates $\$ 20$ trillion will be invested in energy over the next 15 years - what we must do is to ensure that it is not in fossil fuels. We must not pin all our hopes on global politics and clean energy technology, so we must prepare for the worst and adapt. If the right policies are implemented now, a lot of the costs and damage that could be caused by changing climate can be mitigated (Watts et al., 2015). 
Climate change, therefore, challenges the very way we organize our society. Not only does it challenge the concept of the nation-state versus global responsibility, but the perceived advantages of ever increasing world trade (WTO, 2015). Climate change also needs to be seen within the context of the other great challenges of the $21^{\text {st }}$ century: global inequality, population growth, environmental degradation, and global security. To meet these $21^{\text {st }}$ century challenges we must change some of the basic rules of our society to allow us to adopt a much more global and long-term approach, and in doing so develop solutions that benefit everyone.

\section{References}

Allen, M., et al., Warming caused by cumulative carbon emissions towards the trillionth tonne, Nature 458, p 1163-1166 (2009)

BAMS (Bulletin of the American Meteorological Society) Special report 'Explaining Extreme Events from a Climate Perspective' (2017) https://www.ametsoc.org/ams/index.cfm/publications/bulletin-of-the-americanmeteorological-society-bams/explaining-extreme-events-from-a-climate-perspective/

Birchenough, S.N.R., et al., Review of ocean acidification. Foresight Future of the Sea Project, Government Office Science. https://www.gov.uk/government/uploads/system/uploads/attachment_data/file/6455 00/Ocean_Acidification_final_v3.pdf

Coady D, I. W.H. Parry, L. Sears, B. Shang, How Large Are Global Energy Subsidies? IMF working paper (2015) http://www.imf.org/external/pubs/cat/longres.aspx?sk=42940.0

Costello A., et al., Managing the Health effects of climate change, The Lancet, vol 373, 16931733 (2009)

Crowther, T.W., et al., Mapping tree density at a global scale, Nature, 525, 201-205 (2015)

Figueres, C. et al., Emissions are still rising: ramp up the cuts, Nature 564, 27-30 (2018)

Garcia R.A., et al. Multiple dimensions of climate change and their implications for biodiversity, Science, vol. 344, 486-496 (2014) IPCC, Climate Change 2014 - Impacts, Adaptation, and Vulnerability, Contribution of Working Group II to the Fifth Assessment Report of the Intergovernmental Panel on Climate Change (Cambridge University Press, 2014) 
IPCC, Climate Change 2013 - The Physical Science Basis Contribution of Working Group I to the Fifth Assessment Report of the Intergovernmental Panel on Climate Change (Cambridge University Press, 2014)

IPCC, Climate Change 2014a - Impacts, Adaptation, and Vulnerability, Contribution of Working Group II to the Fifth Assessment Report of the Intergovernmental Panel on Climate Change (Cambridge University Press, 2014)

IPCC, Climate Change 2014b - Mitigation of Climate Change, Contribution of Working Group III to to the Fifth Assessment Report of the Intergovernmental Panel on Climate Change (Cambridge University Press, 2014)

IPCC, Special Report on Global Warming of 1.5 ㄷ (2018) https://www.ipcc.ch/sr15/

Lagi, M., Yavni Bar-Yam, K.Z. Bertrand, Yaneer Bar-Yam, UPDATE February 2012 - The Food Crises: Predictive validation of a quantitative model of food prices including speculators and ethanol conversion. arXiv:1203.1313, (2012).

Lewis, S. L. \& Maslin, M. A. Defining the Anthropocene. Nature 519, 171-180, doi:10.1038/nature14258 (2015).

Lewis, S. L. \& Maslin, M. A. The Human Planet: How we caused the Anthropocene, Penguin (2018)

Lewis, S. L. et al., Restoring natural forests is the best way to remove atmospheric carbon, Nature, 568 , 25-28 (2019)

Maslin M.A., Cascading uncertainty in Climate Change models and its implications for policy, Geographical Journal 179, 264-271 (2013)

Mark Maslin (2014) Climate Change, VSI, Oxford University Press, ISBN 978-0-19-871904-5, p160

National Climate Assessment. U.S. Global Change Research Program (2018) https://nca2018.globalchange.gov/

Painter, A. and Thoung, C., Creative citizen, creative state: The principled and pragmatic case for a Universal Basic Income (2015)

https://www.thersa.org/discover/publications-and-articles/reports/basic-income

Papworth, A., S. Randalls, M.A. Maslin, Is climate change the greatest threat to global health? Geographical Journal DOI: 10.1111/geoj.12127 (2014)

Samples, I., World faces 'perfect storm' of problems by 2030, chief scientist to warn, Guardian newspaper (2009) 
https://www.theguardian.com/science/2009/mar/18/perfect-storm-john-beddingtonenergy-food-climate (accessed on 3/4/19)

Stern, N., The Economics of Climate Change: The Stern Review (Cambridge University Press, p. 692 (2007)

Stephenson, J., S. Crane, C. Levy, and M.A. Maslin, Population, Development and Climate Change: links and effects on human health? Lancet Online July 11, 2013 http://dx.doi.org/10.1016/S0140-6736(13)61460-9 (2013)

Taylor, R.G., 2014. When wells run dry. Nature, Vol. 516, 179-180.

Taylor, R.G., Scanlon, B.R., Doell, P., Rodell, M., van Beek, L., Wada, Y., Longuevergne, L., LeBlanc, M., Famiglietti, J.S., Edmunds, M., Konikow, L., Green, T., Chen, J., Taniguchi, M., Bierkens, M.F.P., MacDonald, A., Fan Y., Maxwell, R., Yechieli, Y., Gurdak, J., Allen, D., Shamsudduha, M., Hiscock, K., Yeh, P., Holman, I. and Treidel, H., 2013.

Groundwater and climate change. Nature Climate Change, Vol. 3, 322-329.

UKCP (2018), UK Climate Projections, Met Office, https://www.metoffice.gov.uk/research/collaboration/ukcp

van Vuuren D P et al. 2011 The representative concentration pathways: an overview Climatic Change 109 5-31

Waters, C. N. et al. The Anthropocene is functionally and stratigraphically distinct from the Holocene. Science 351, 137, doi:10.1126/science.aad2622 (2016).

Watts N. et al. (including M.A Maslin) Lancet Commission on Health and Climate Change: Policy Responses to Protect Public Health. The Lancet Published online June 23 (2015) http://dx.doi.org/10.1016/S0140-6736(15)60854-6

WTO (2015) World Trade Organization assessment of impacts of world trade on climate change. https://www.wto.org/english/tratop_e/envir_e/climate_impact_e.htm

Figure 1. The Greenhouse effect (adapted from Maslin, 2014)

Figure 2. Variation of atmospheric carbon dioxide since 1958 measured at Mauna Loa in Hawaii (adapted from NOAA, 2018).

Figure 3. Global carbon stores and fluxes (adapted Maslin, 2014) 
Figure 4. Variation of the Earth's surface temperature over the last 150 years (adapted from NOAA, 2018).

Figure 5. Representative concentration pathways A) Giga Tonnes of carbon emitted per year and B) Giga Tonnes of carbon emitted in total (IPCC 2013; 2014b).

Figure 6. Past and projected future changes in A) global temperature and B) global sea level (adapted from IPCC 2013).

Figure 7. Past and future carbon emissions illustrating the reduction in emission required to reduce the effects of global warming (data from IPCC, 2013; 2014b and 2018). 

Global Ocean surface pH

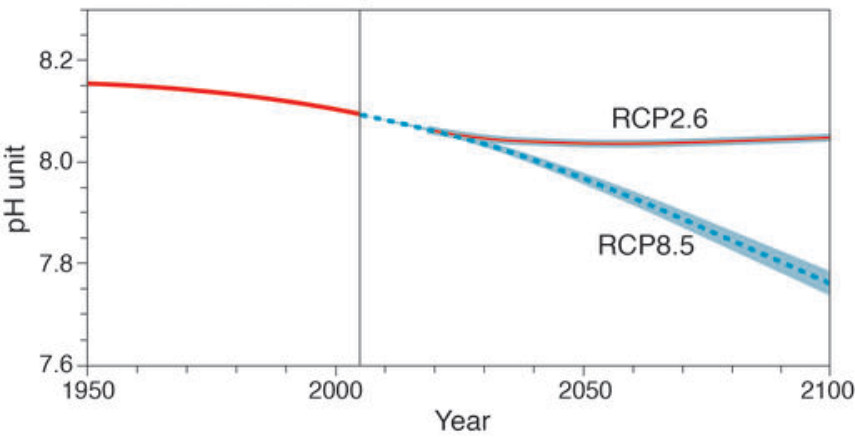


Atmospheric $\mathrm{CO}_{2}$ at Mauna Loa Observatory

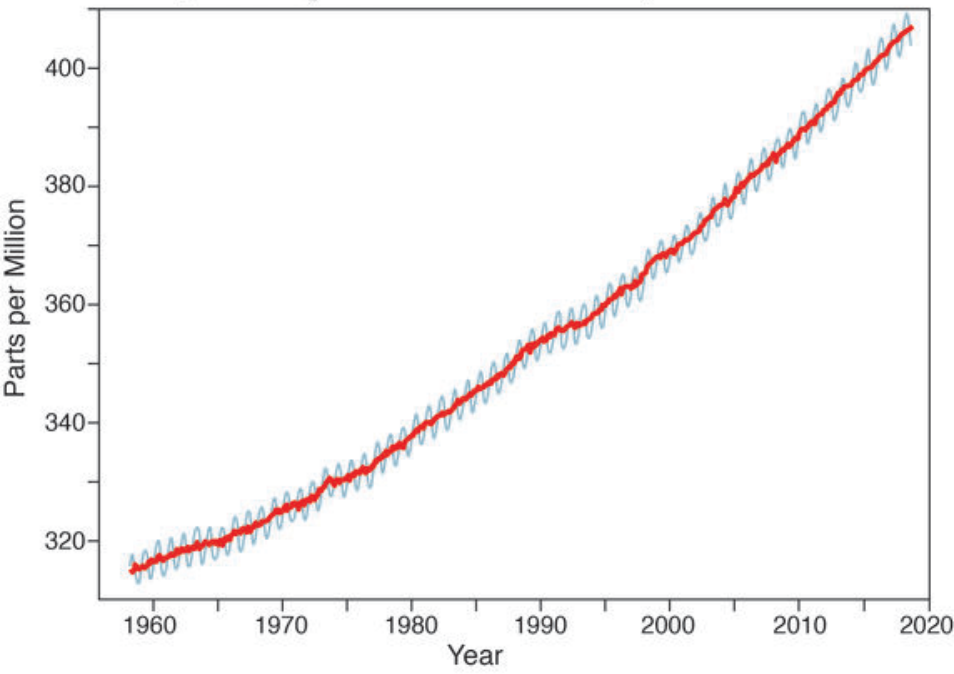


Short Wave (Light \& UV)

Radiation

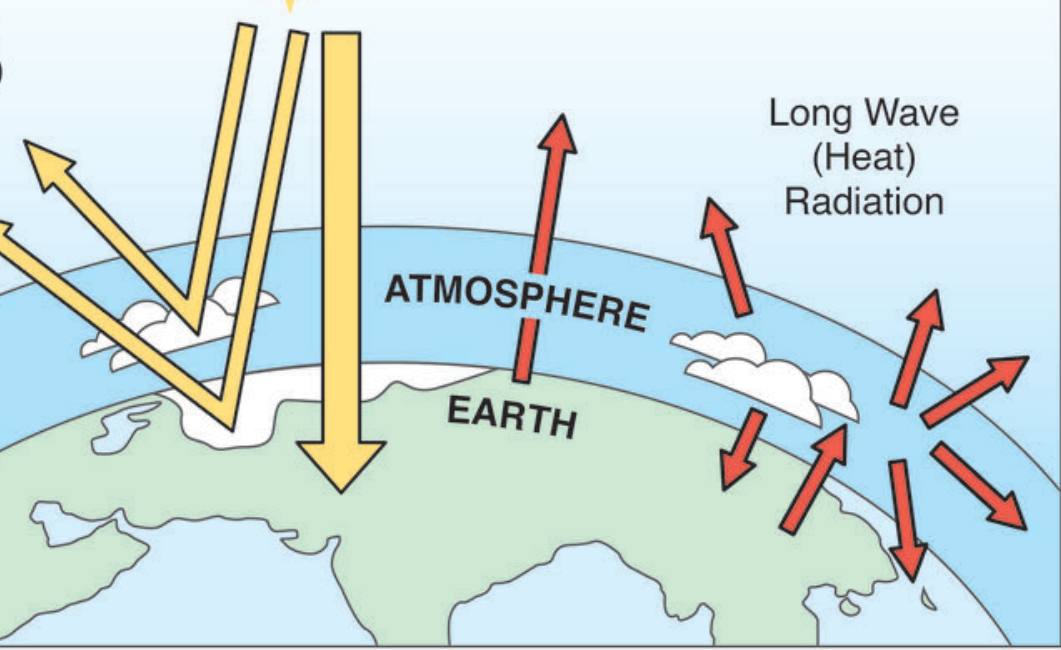


a) Global average surface temperature change

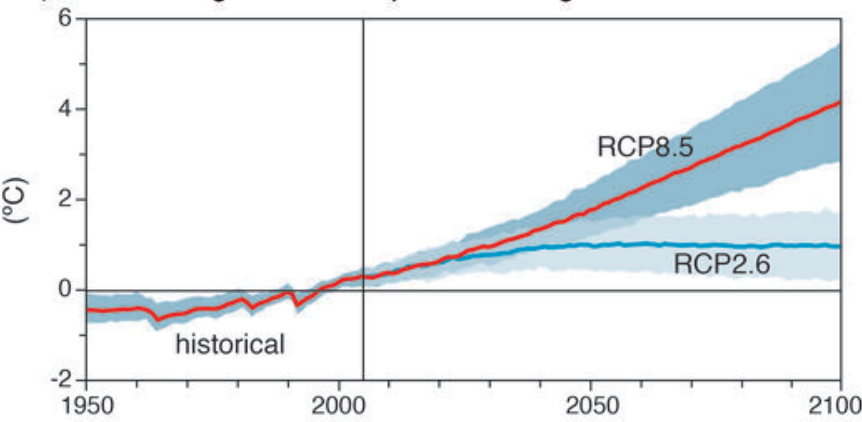

b) Global mean sea level rise

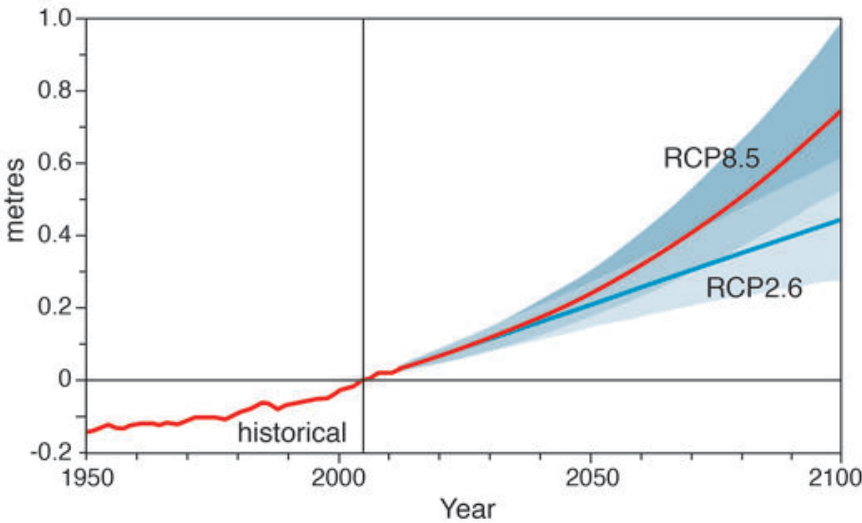


Past and future carbon emissions

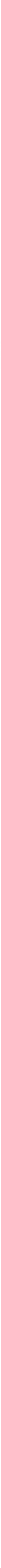

